\title{
Dossier: Estudios actuales de lingüística histórica en Iberoamérica $^{1}$
}

La lingüística histórica es, sin duda alguna, una de las disciplinas más antiguas en el ámbito de las Humanidades. Nacida en el seno de Europa y en estrecho vínculo con la lingüística comparativa, especialmente de la mano de grandes lingüistas como Franz Bopp, Schlegel, los hermanos Grimm, August Schleicher y Rasmus Rask, no ha dejado de desarrollarse durante más de dos siglos, con mayores y menores períodos de auge. Pero a pesar de su larga data, no ha sido sino hasta hace apenas algunas décadas que esta disciplina ha dado dos importantes pasos. El primero de ellos, en lo relativo a los niveles de análisis, corresponde a la investigación sobre el cambio sintáctico, el último en incorporarse con una perspectiva científica, estimulado, en especial, por una ola creciente de trabajos contrastivos translingüísticos, fundamentalmente tipológico-funcionalistas. Este impulso, y el creciente aporte de los trabajos centrados en la reconstrucción interna y no solo en el método comparativo tradicional, permitieron una importante revitalización de la lingüística histórica en el ámbito indoeuropeo y a la vez un acercamiento translingüístico más homogéneo. El segundo gran paso tiene que ver con la apertura de la disciplina hacia las lenguas de otras familias y, en lo que nos concierne a nosotros especialmente, la incorporación de la lingüística histórica en el contexto sudamericano, al principio en estrecho vínculo con la dialectología hispanoamericana y solo posteriormente con el trabajo con lenguas originarias.

Es precisamente por esta trayectoria reciente que resulta tan importante la formación de redes entre los especialistas de nuestro contexto geográfico, tanto de aquellos trabajando en lenguas originarias de Sudamérica como en lenguas indoeuropeas y otras familias lingüísticas. De allí que decidiéramos organizar en 2015 el Coloquio de Lingüística Histórica, patrocinado por la Pontificia Universidad Católica de Chile, al

1 Tanto la elaboración de la introducción a este dossier como el coloquio que lo origina se realizaron en el marco del proyecto CONICYT-FONDECYT posdoctoral 3150246 y del proyecto "Estudios de formación nominal: lenguas paleohispánicas e indoeuropeas antiguas” (FFII 2009-13292-Co3-02). 
cual asistieron importantes investigadores del país y del exterior. El objetivo de ese encuentro fue el de establecer vínculos entre investigadores y el de aportar colaborativamente a esta disciplina en nuestra región. Fruto de este encuentro fue, en primer lugar, la enriquecedora discusión que pudimos establecer y, en segundo lugar, el llamado a las comunicaciones que conforman este monográfico.

Los autores que colaboran en este dossier abordan diferentes ámbitos relacionados con la lingüística histórica y dan cuenta de algunas de las líneas de trabajo que se llevan adelante actualmente en Sudamérica y España. Como se verá, en términos generales los artículos se organizan según un eje diacrónico y presentan investigaciones no solo sobre diferentes niveles de análisis de las lenguas antiguas y del desarrollo general del español (y, en particular, del español de Chile), sino también en el ámbito de las lenguas originarias y del desarrollo de las ideas lingüísticas. Los artículos se engloban también en tres grandes categorías: a) estudios en torno al español, b) estudios de lenguas originarias de Sudamérica y c) estudios en torno a las lenguas indoeuropeas antiguas.

El primer bloque del dossier se abre con el artículo "Expresión del futuro en el español oral de Chile actual: aproximación cognitivista a un caso de gramaticalización", de Matías Jaque (Universidad de Chile), quien demuestra a partir de la comparación de dos corpus orales del español de Chile (de 1970 y 2009) que las formas del futuro en -ré se encuentra en franco retroceso como exponente de temporalidad, conservando únicamente valores modales epistémicos, a diferencia de las formas perifrásticas de ir a + infinitivo, establecidas en la oralidad como marca canónica del tiempo futuro. En este trabajo, el autor propone que los cambios en el sistema de expresión de la temporalidad no se explican simplemente a partir de una concepción pragmático-discursiva de la gramaticalización, ni sobre el empleo de metáforas conceptuales, sino que están motivados por la compensación entre dos formas de cognición temporal: la experiencia directa y centrada en el presente del tiempo (tiempo fenomenológico) y la organización secuencial deíctica de intervalos y eventos con independencia de la experiencia del hablante (tiempo simbólico), siendo la segunda una derivación de la primera. El análisis de los datos efectuado por Jaque permite proponer como hipótesis una tendencia de cambio extensible a otras perífrasis de expresión temporal, en la medida en que la gramaticalización de las distintas unidades léxicas no se da de forma aislada, sino que opera como un conjunto armónico guiado, en 
última instancia, por motivaciones cognitivas relacionadas con nuestra percepción temporal.

Con el siguiente artículo, "Representaciones del cambio lingüístico en Chile durante el siglo XIX: ¿progreso o decadencia?”, de Darío Rojas (Universidad de Chile), nos movemos hacia el ámbito de las ideas lingüísticas y la glotopolítica histórica. En este caso, el autor investiga cómo se percibe el cambio lingüístico en el contexto del Chile de la segunda mitad del siglo XIX y concluye que podía ser considerado como decadencia o como progreso según se percibiera respectivamente un carácter amenazante o no de la unidad lingüística del mundo hispanohablante.

Ya moviéndonos hacia la historia general del español, Francisca Toro (Pontificia Universidad Católica de Chile) propone con su artículo, "Régimen directo y preposicional del verbo cuidar en castellano: una aproximación histórica", que el cruce semántico y sintáctico de los verbos cuidar y curar entre los siglos XII y XV permite explicar la actual alternancia de cuidar entre una estructura preposicional (cuidar de una persona) y otra con complemento directo (cuidar a una persona). A partir de datos extraídos del Corpus Diacrónico del Español (CORDE), la autora concluye que la transferencia semántica de curar a cuidar ocurrida durante finales de la Edad Media induce, al mismo tiempo, un cambio sintáctico, en tanto cuidar empieza a admitir objetos animados en construcciones de régimen directo, lo cual en el período más temprano estaba limitado a curar.

El siguiente bloque está compuesto por el trabajo de Roberto Bahamonde (Investigador independiente), "Pillañ peuma rruaín: el mapudungún en Chiloé a fines del siglo XIX según los collag", y el de Antônio Mello y Andreas Kneip (Universidade de Brasília, Universidade Federal do Tocantins), "Novas evidências linguísticas (e algumas arqueológicas) que apontam para a origem dos povos tupi-guarani no leste amazônico". En el primero, el autor ofrece una caracterización fonético-fonológica, gramatical y léxica del mapudungún empleado en los collag recopilados en el mar interior de Chiloé por Juan Elías Necul alrededor de 1887, pocos años antes de la extinción local del idioma. A partir de su análisis lingüístico y filológico, Bahamonde sostiene que la variedad presente en estos textos no compartía los rasgos diferenciales del chesüngun hablado actualmente en la región de Los Lagos, que los sufijos de las formas no finitas se habían lexicalizado o adoptado otras funciones y que la mayor parte del vocabulario no difiere del vocabulario corriente en otras variedades de la lengua mapuche. Por su parte, Mello y Kneip, en un trabajo en el que los 
datos lingüísticos dialogan con la arqueología, discuten diversas hipótesis acerca del origen y dispersión de los pueblos de la familia Tupi-Guaraní y proponen, a partir del análisis de diferentes parámetros lingüísticos, que la zona de mayor diversidad Tupi-Guaraní no coincide con la del tronco Tupi, como sugieren propuestas previas. Los autores invitan a pensar que si se desplaza la región de origen de los proto-Tupi-Guarani hacia el este amazónico es mucho más plausible que los Tupinambá hayan alcanzado la costa y se hayan dispersado por el litoral desde el norte.

El tercer bloque comienza con el artículo "Los adjetivos en - $u$ - en armenio clásico”, de Ángel López (Universidad Complutense de Madrid), quien ofrece un análisis exhaustivo de estos adjetivos y sus derivados. Aquí el autor muestra la peculiaridad de estos casos, que presentan una flexión heteróclita en lugar de una flexión común, alejándose de esta manera de lo esperable en otras lenguas indoeuropeas antiguas como el griego y el védico.

A continuación, el artículo "La expresión de la función semántica de procedencia en las comedias de Plauto", de Berta González (Universidad Complutense de Madrid), hace hincapié en aspectos semánticos del sistema casual del latín preclásico y sostiene que, para poder comprender mejor el comportamiento de los casos, un análisis a partir de valores semánticos es mucho más efectivo que partir de los listados de usos de cada caso, como proponía el análisis tradicional, puesto que en este último no se pueden extraer los parámetros que determinan su significado. Con esta propuesta, González pretende poner en evidencia cuáles son estos parámetros cuando el ablativo latino expresa la Procedencia.

Finalmente, el artículo de Verónica Orqueda (Pontificia Universidad Católica de Chile), "Focalización con y sin incidencia argumental en la formación de palabras: el aporte de algunas lenguas indoeuropeas antiguas", analiza formaciones con intensificadores en védico y griego antiguo a la luz de tres propuestas de análisis provenientes de trabajos en torno a diferentes lenguas modernas (Felíu 2003 y 2005; Mutz 2003 y 2011; y König 2011). La autora sostiene que en los compuestos analizados, y a diferencia de lo que ocurre con algunas lenguas modernas, la incidencia del prefijo en la estructura argumental no es necesariamente un requisito, pues existen también formaciones cuyo primer elemento funciona como focalizador sin estructura argumental. A partir del contraste entre los datos de las lenguas analizadas y de la tripartición de formaciones (a) reflexivas (ingl. self-regulation), (b) anticausativas (esp. autoaplicador) y 
(c) de focalización, se propone una subdivisión de estas últimas según sean con (español autogestión de los negocios, védico svakșatra) o sin estructura argumental (alemán Eigenblut, griego antiguo autokasignétēe).

Verónica Orqueda 